\title{
COMPARISON OF THE EFFECT OF DAPAGLIFLOZIN ON CONTRAST TO STANDARD THERAPY OF THE PATIENTS WITH TYPE 2 DIABETES MELLITUS AND CONCOMITANT OBESITY, THEIR EFFECT ON LABORATORY AND ANTHROPOMETRIC PARAMETERS
}

DOI: 10.36740/WLek202003109

\author{
Taras I. Griadil, Ivan V. Chopey, Kristian 0. Debreceni, Mykhaylo M. Hechko, Yaroslav 0. Mykhalko, Snizhana V. Feysa \\ STATE HIGHER EDUCATIONAL ESTABLISHMENT «UZHHOROD NATIONAL UNIVERSITY», UZHHOROD, UKRAINE
}

\begin{abstract}
The aim: Evaluate clinical and laboratory parameters of the patients with type 2 diabetes mellitus and concomitant obesity after a course of dapagliflozin treatment and compare with a standard treatment regimen.

Materials and methods: Conducted a comprehensive clinical laboratory examination and measurement of the anthropometric parameters of the patients with type 2 diabetes mellitus and concomitant obesity, with subsequent statistical calculations.

Results: The data obtained at different stages of the study revealed a statistically significant effect of glucose treatment and glycosylated hemoglobin (HbA1c). Since the 6th month of dapagliflozin treatment, we have shown a tendency to lose weight compared to baseline in this group of patients and controls.

Conclusions: Type 2 diabetes mellitus and obesity significantly increase the risk of developing a number of complications. Complex control and effects on clinical laboratory and anthropometric parameters can statistically significantly influence the development of the complications, and in this context, dapaglifloflozin showed statistically better results than standard metformin monotherapy.
\end{abstract}

KEY WORDS: type 2 diabetes mellitus, obesity, treatment, diagnostics

Wiad Lek. 2020;73(3):457-461

\section{INTRODUCTION}

Type 2 diabetes mellitus (T2DM) is a chronic disease characterized by insufficient amount of pancreatic insulin production, or the production of insulin is not used effectively [1]. According to the World Health Organization (WHO), as of 2016, about 8.5\% (422 million) of the world's population suffer from T2DM worldwide [2]. It should be noted that with adequate health monitoring, about the $10-25 \%$ of T2DM can be prevented, including 2.34 million cases of depressive disorders [3].

In itself, T2DM is an extremely complex medical and social problem of today, since this disease contributes to a number of serious complications: limb amputation, loss of vision, cardiovascular disease, renal failure, damage to the nervous system, etc. [4].

The main diagnostic criteria for T2DM (according to the American Diabetes Association (ADA) 2020) [5]:

- 2 -h fasting plasma glucose $\geq 200 \mathrm{mg} / \mathrm{dL}$ ( $11.1 \mathrm{mmol} / \mathrm{L})$ during oral glucose tolerance test. (Using a glucose load containing the equivalent of 75 gram anhydrous glucose dissolved in water. In the absence of unequivocal hyperglycemia, diagnosis requires two abnormal test results from the same sample or in two separate test samples) or - Fasting plasma glucose (FPG) $\geq 126 \mathrm{mg} / \mathrm{dL}(7.0 \mathrm{mmol} / \mathrm{L})$. Fasting is defined as no caloric intake for at least 8 hours or - $\mathrm{HbAlC} \geq 6.5 \%$ ( $48 \mathrm{mmol} / \mathrm{mol}$ ) or
- In a patient with classic symptoms of hyperglycemia or hyperglycemic crisis, a random plasma glucose $\geq 200 \mathrm{mg} /$ $\mathrm{dL}(11.1 \mathrm{mmol} / \mathrm{L})$.

There are a number of recommendations for the treatment of T2DM by The European Foundation for the Study of Diabetes (EFSD), ADA [6], International Diabetes Federation (IDF) [7], but despite some differences, they all agree on because the treatment should be complex and include: diet therapy, rational step-by-step pharmacotherapy (starting with metformin and depending on the level of glycosylated hemoglobin (HbAlc) after treatment - transition to combinations with the following drug groups), dosed physical activity and altered physical activity .

Dapagliflozin is a selective and inverse inhibitor of type 2 glucose cotransporter (SGLT2) [8]. Dapagliflozin lowers glucose levels both after ingestion and on an empty stomach by reducing renal glucose absorption and as a consequence of its excretion in the urine [8]. However, this medicine does not interfere with the normal production of endogenous glucose in response to hypoglycemia and acts independently of insulin secretion and action. Urinary glucose excretion induced by dapagliflozin is associated with calorie loss and weight loss [9]. Suppression of the co-transport of glucose and sodium by dapagliflozin may be accompanied by minor urine output and temporary excretion of sodium by urine [8]. 
A number of the clinical trials (CDs) have been conducted, the analysis of the obtained data of which testify to the safety of this medicine. One of the CDs is the cardiovascular events (DECLARE) assessment with dapagliflozin at a dosage of $10 \mathrm{mg}$ compared with placebo with the participation of 17,160 patients with T2DM with / without established cardiovascular disease to evaluate the effects on the cardiovascular events [10]. CVD-REAL 3 Multinational Cohort Study Data Analysis, which included the information on more than 65,000 patients in Israel, Italy, Japan, Taiwan and the United Kingdom, the primary purpose of which was to compare SGLT2 drugs and other antipyretics, and included measurements and estimation of glomerular filtration rate (eGFR) before and after (within 180 days) [11]. The study provided global, real-world evidence for the evaluation of the efficacy and safety of SGLT2 drugs, in particular closely related to a lower risk of major renal events [11].

According to the 2016 WHO data, approximately 1.9 billion people of the age 18 and over are overweight, 600 million of whom are obese [12]. At present, $35-36 \%$ of men, $41 \%$ of women and $15-16 \%$ of children have obesity or overweight in Ukraine, while the tendency to increase of these indicators remains [13].

It should be noted that the consequences of obesity may be: cardiovascular diseases (hypertension, heart failure, atherosclerosis), neurological (stroke, polyneuropathy), musculoskeletal disorders (arthritis, psychiatric syndrome, pain syndrome), eating disorders), gastrointestinal (gastroesophageal reflux disease, liver cirrhosis), endocrinological (T2DM, infertility), oncological diseases, etc. [14].

The main diagnostic criteria for obesity are measurements of body height and weight, followed by the BMI calculations. If $B M I$ is $\geq 30 \mathrm{~kg} / \mathrm{m}^{2}$, it can be regarded as obesity and therefore classified according to the degree of obesity [15]. Additionally measure the waist circumference (WC) and hip circumference (HC), followed by the calculation of their ratio (WC/ HC). According to the WHO, the WC for men is $94 \mathrm{~cm}$ and for women is $80 \mathrm{~cm}$, indicating that they are at increased risk of serious illness, while $102 \mathrm{~cm}$ and $88 \mathrm{~cm}$ respectively are regarded as extremely high risk [16]. The coefficient waist-to-hip ratio (WHR) obtained by the dividing $\mathrm{WC}(\mathrm{cm})$ by $\mathrm{HC}(\mathrm{cm})$ indicates health risks, but they increase dramatically if this ratio for men is above 0.95 for women - 0.85 [17]. Additionally, it is recommended to determine the thickness of the fatty fold. It is possible to instrumentally determine the extent of the distribution of adipose tissue in the human body by ultrasound, magnetic resonance imaging, computed tomography or bioimpandance, but these methods are expensive and do not require routine examination in each patient. For this reason, the search for new anthropometric indicators and obesity-related indicators is being continued, which will be able to better assess the degree of obesity and, accordingly, the distribution of adipose tissue $[18,19]$.

\section{THE AIM}

To evaluate the clinical and the laboratory parameters of the patients with T2DM and concomitant obesity after treatment with the dapagliflozin and compare with the standard.

\section{MATERIALS AND METHODS}

Selection of the patients with T2DM and a combination of obesity was performed on the basis of the hospital of the therapeutic department of the Municipal non-profit enterprise of the Uzhhorod Regional Clinical Hospital of the Uzhhorod Regional Council of Transcarpathian region and at outpatient treatment department of the therapy and the family medicine of the Faculty of Postgraduate And Pre-University Education of the State Higher Educational Establishment «Uzhhorod National University».

During November 2016 and January 2020, 137 patients were diagnosed with T2DM and concomitant obesity. The diagnosis criteria for T2DM were established on the basis of the ADA recommendations, but instead obesity was performed in accordance with the $B M I \geq 30 \mathrm{~kg} / \mathrm{m}^{2}$ with subsequent distribution into groups by degree of the obesity (I, II and III degrees respectively).

All the patients underwent the comprehensive treatment, which included dietary therapy, dosed physical activities (at least 30 minutes per day) and pharmacotherapy with metformin $850 \mathrm{mg} \times 2$ times daily in the I group $(n=71)$, instead the patients of the group II $(n=66)$ in addition to the complex treatment additionally received dapagliflozin $10 \mathrm{mg} x$ once a day, and 18-month follow-up with 3 and 6-month follow-up, on the 12th, the 18th of the month.

The statistical processing of the research results was performed using the program software International Business Machines Corporation Statistical Package for the Social Sciences Statistics. The statistical analysis of the materials, the summary and also the summary of the conclusions were made by the method of the variation statistics, taking into account the average values (mod, median, arithmetic mean) and the average error $(\mathrm{M} \pm \mathrm{m})$, with the estimation of the reliability of the values by the Student's t-criterion, as well as with the determination of the correlation coefficient using the Pearson's paired method to identify the relationships between the obtained indicators. For the minimum threshold of probability, the values $\mathrm{p}<0.05$ were taken.

The whole set of the surveys were in accordance with the Articles 3, 44 of the Fundamentals of the Legislation of Ukraine on Healthcare, the Articles 7, 8 of the Law of Ukraine "On Medicines", the Law of Ukraine "On Protection of Personal Data", taking into account the requirements of the European Parliament and Council Directives 2001/ 20 / EU of April 4, 2001, 2001/83 / EC of November 6,2001, the Decisions of the European Parliament and of the Council 1901/2006 of December 12,2006 and 1902/2006 of December 20,2006, ICH GCP, International Ethical Principles for Biomedical human-related research and physician code of conduct, and order in the Ministry of Health of Ukraine No. 690 of September 23, 2009, as well as the order of the Ministry of Health of Ukraine No. 1118 of December 21, 2012, unified clinical protocol of the primary and the secondary (specialized) medical care of T2DM.

\section{RESULTS}

Those included in this study were $\geq 40$ years old. The mean age of the patients in the 1 st group was $52.1 \pm 1.1$ years, 
Table I. Anthropometrical parameters in group I and II.

\begin{tabular}{|c|c|c|c|c|c|c|}
\hline & \multicolumn{3}{|c|}{ Group I (n=71) } & \multicolumn{3}{|c|}{ Group II (n=66) } \\
\hline & $\begin{array}{c}\text { Total } \\
(n=71)\end{array}$ & $\begin{array}{l}\text { Men's } \\
(n=25)\end{array}$ & $\begin{array}{c}\text { Females } \\
(n=46)\end{array}$ & $\begin{array}{l}\text { Total } \\
(n=66)\end{array}$ & $\begin{array}{l}\text { Men's } \\
(n=27)\end{array}$ & $\begin{array}{c}\text { Females } \\
(n=39)\end{array}$ \\
\hline $\mathrm{BMI}^{\mathrm{B}}\left(\mathrm{kg} / \mathrm{m}^{2}\right)$ & $32,64 \pm 0,19$ & $32,54 \pm 0,27$ & $32,70 \pm 0,25$ & $32,74 \pm 0,22$ & $32,44 \pm 0,37$ & $32,94 \pm 0,28$ \\
\hline$W C^{B}(\mathrm{~cm})$ & $109,97 \pm 1,44$ & $110,96 \pm 1,15$ & $109,43 \pm 2,14$ & $109,06 \pm 1,38$ & $110,62 \pm 1,17$ & $107,97 \pm 2,19$ \\
\hline $\mathrm{HC}^{\mathrm{B}}(\mathrm{cm})$ & $104,0 \pm 0,98$ & $99,88 \pm 0,96$ & $106,3 \pm 1,31$ & $103,7 \pm 1,02$ & $99,29 \pm 0,81$ & $106,8 \pm 1,45$ \\
\hline $\mathrm{WHR}^{\mathrm{B}}$ & $1,06 \pm 0,01$ & $1,11 \pm 0,01$ & $1,04 \pm 0,02$ & $1,05 \pm 0,01$ & $1,11 \pm 0,01$ & $1,06 \pm 0,02$ \\
\hline $\mathrm{BMI}^{\mathrm{M} 3}\left(\mathrm{~kg} / \mathrm{m}^{2}\right)$ & $31,64 \pm 0,19$ & $31,54 \pm 0,27$ & $31,70 \pm 0,25$ & $31,74 \pm 0,22$ & $31,44 \pm 0,37$ & $31,94 \pm 0,28$ \\
\hline$W C^{M 3}(\mathrm{~cm})$ & $107,5 \pm 1,43$ & $108,5 \pm 1,22$ & $106,9 \pm 2,12$ & $106,7 \pm 1,39$ & $108,4 \pm 1,19$ & $105,5 \pm 2,19$ \\
\hline $\mathrm{HC}^{\mathrm{M} 3}(\mathrm{~cm})$ & $101,50 \pm 0,99$ & $97,36 \pm 1,02$ & $103,76 \pm 1,33$ & $101,40 \pm 1,05$ & $96,703 \pm 0,84$ & $104,66 \pm 1,48$ \\
\hline WHR $^{\mathrm{M} 3}$ & $1,06 \pm 0,01$ & $1,11 \pm 0,01$ & $1,03 \pm 0,02$ & $1,06 \pm 0,01$ & $1,12 \pm 0,01$ & $1,04 \pm 0,02$ \\
\hline $\mathrm{BMI}^{\mathrm{M} 6}\left(\mathrm{~kg} / \mathrm{m}^{2}\right)$ & $30,65 \pm 0,19$ & $30,54 \pm 0,27$ & $30,71 \pm 0,25$ & $30,74 \pm 0,22$ & $30,45 \pm 0,37$ & $30,95 \pm 0,28$ \\
\hline$W C^{M 6}(\mathrm{~cm})$ & $104,2 \pm 1,44$ & $105,4 \pm 1,24$ & $103,6 \pm 2,12$ & $103,6 \pm 1,40$ & $105,3 \pm 1,35$ & $102,3 \pm 2,18$ \\
\hline $\mathrm{HC}^{\mathrm{M} 6}(\mathrm{~cm})$ & $99,52 \pm 0,99$ & $95,52 \pm 1,01$ & $101,6 \pm 1,33$ & $99,5 \pm 1,04$ & $94,96 \pm 0,87$ & $102,6 \pm 1,46$ \\
\hline WHR ${ }^{\mathrm{M} 6}$ & $1,05 \pm 0,01$ & $1,10 \pm 0,01$ & $1,02 \pm 0,02$ & $1,05 \pm 0,01$ & $1,11 \pm 0,01$ & $1,03 \pm 0,02$ \\
\hline BMI ${ }^{\mathrm{M} 12}\left(\mathrm{~kg} / \mathrm{m}^{2}\right)$ & $30,47 \pm 0,16$ & $30,45 \pm 0,22$ & $30,51 \pm 0,25$ & $29,79 \pm 0,22^{*}$ & $29,63 \pm 0,32^{* 1}$ & $30,15 \pm 0,24^{* 2}$ \\
\hline WC ${ }^{M 12}(\mathrm{~cm})$ & $103,5 \pm 1,32$ & $103,1 \pm 1,27$ & $102,4 \pm 2,12$ & $101,2 \pm 1,40$ & $103,3 \pm 1,33^{* 1}$ & $100,3 \pm 2,14^{* 2}$ \\
\hline $\mathrm{HC}^{\mathrm{M} 12}(\mathrm{~cm})$ & $97,35 \pm 1,32$ & $94,71 \pm 1,01$ & $99,3 \pm 1,42$ & $97,1 \pm 1,05$ & $93,96 \pm 0,88$ & $100,1 \pm 1,39 * 2$ \\
\hline WHR $^{\mathrm{M} 12}$ & $1,03 \pm 0,02$ & $1,09 \pm 0,02$ & $1,01 \pm 0,01$ & $1,01 \pm 0,02 *$ & $1,05 \pm 0,01^{* 1}$ & $1,01 \pm 0,02$ \\
\hline $\mathrm{BMI}^{\mathrm{M} 18}\left(\mathrm{~kg} / \mathrm{m}^{2}\right)$ & $30,31 \pm 0,23$ & $30,41 \pm 0,12$ & $30,47 \pm 0,29$ & $29,72 \pm 0,29 *$ & $29,59 \pm 0,37^{* 1}$ & $29,87 \pm 0,25^{* 2}$ \\
\hline WC ${ }^{M 18}(\mathrm{~cm})$ & $101,4 \pm 1,28$ & $101,4 \pm 1,31$ & $101,2 \pm 2,09$ & $101,1 \pm 1,32 *$ & $102,7 \pm 1,33^{* 1}$ & $97,2 \pm 1,99 * 2$ \\
\hline $\mathrm{HC}^{\mathrm{M} 18}(\mathrm{~cm})$ & $95,78 \pm 1,21$ & $93,68 \pm 1,2$ & $97,3 \pm 1,33$ & $94,57 \pm 1,03$ & $91,63 \pm 0,88$ & $97,6 \pm 1,25$ \\
\hline WHR ${ }^{\mathrm{M} 18}$ & $1,02 \pm 0,01$ & $1,07 \pm 0,01$ & $1,00 \pm 0,01$ & $1,00 \pm 0,03^{*}$ & $1,03 \pm 0,02^{* 1}$ & $1,00 \pm 0,05^{* 2}$ \\
\hline
\end{tabular}

Note: B - patient data at baseline; M - 3, 6, 12, 18 - patient data for 3, 6, 12, 18 months of observation of the respective patient groups; ${ }^{*}$ - statistically significant difference when comparing the indicators between the respective groups I and II $(p<0.05)$; where * 1 - between men and * 2 between women; BMI - Body Mass Index; WC - Waist circumference; HC - The hip circumference; WHR - waist-to-hip ratio.

compared with $54.5 \pm 1.2$ years of the patients in the 2 nd group ( $\mathrm{p}>0.05)$. The ratio of men and women in the group I is 25 men and 46 women versus 27 men and 39 women in the group II. The mean duration of T2DM in group I was $15.3 \pm 2.1$ years, as opposed to $16.7 \pm 1.9$ years.

According to the data obtained as a result of the measuring anthropometric parameters of the patients of the 1 st and the 2nd group at the beginning of the study, no statistically significant difference was found between them ( $>0.05)$. The BMI at the beginning of the study in the group I was $32.64 \pm 0.19 \mathrm{~kg} / \mathrm{m} 2$, respectively, $32.74 \pm$ $0.22 \mathrm{~kg} / \mathrm{m}^{2}$ in the group II. The WC index in group I at the beginning of the study was $109.97 \pm 1.44 \mathrm{~cm}$, respectively $109.06 \pm 1.38 \mathrm{~cm}$ in the group II. WHR in the group I was $1.06 \pm 0.01$ and $1.05 \pm 0.01$, respectively, in the group II.

It is noteworthy that, starting from 12 months after the completing the course of the complex treatment and at the 18th month, the visit of the completion of the treatment and observation, between the anthropometric parameters (AP) of the patients of the 1st and the 2 nd group, there was a statistically significant difference, the same the dynamics were also observed when comparing the sex between the two groups $(p<0.05)$.

Analyzing the biochemical parameters of the blood, namely hydrocarbon metabolism, there is a tendency to decrease fasting plasma glucose (FPG) and $\mathrm{HbA1C}$, but the target HbA1C levels were reached only at the 18th month of the comprehensive treatment. At the same time, statistically significant results were recorded when the comparing results of the I and the II groups $(p<0.05)$, as well as when comparing by sex $(\mathrm{p}<0.05)$, despite the fact that at the beginning of the study there was no statistically significant difference $(\mathrm{p}>0.05)$.

The other biochemical parameters obtained at different stages of the study did not reveal the statistically significant changes in the indicators of the groups I and II ( $p>0.05)$.

A rather interesting finding at the beginning of the study was that thyroid hormone levels in the group I revealed $22 \%$ of the patients with the subclinical hypothyroidism $(\mathrm{SCH})$, while in the group II it was detected in $27 \%$ of the patients.

\section{DISCUSSION}

In spite of the data obtained by us, which indicate the safety of use of the dapagliflozin, the literature describes cases and incidence of the adverse events with the cardiovascular events and the bacterial urinary tract infections after the use of dapagliflozin of the patients with T2DM. Further studies will focus on the study and comparison of 
Table II. FPG and HbA1C levels

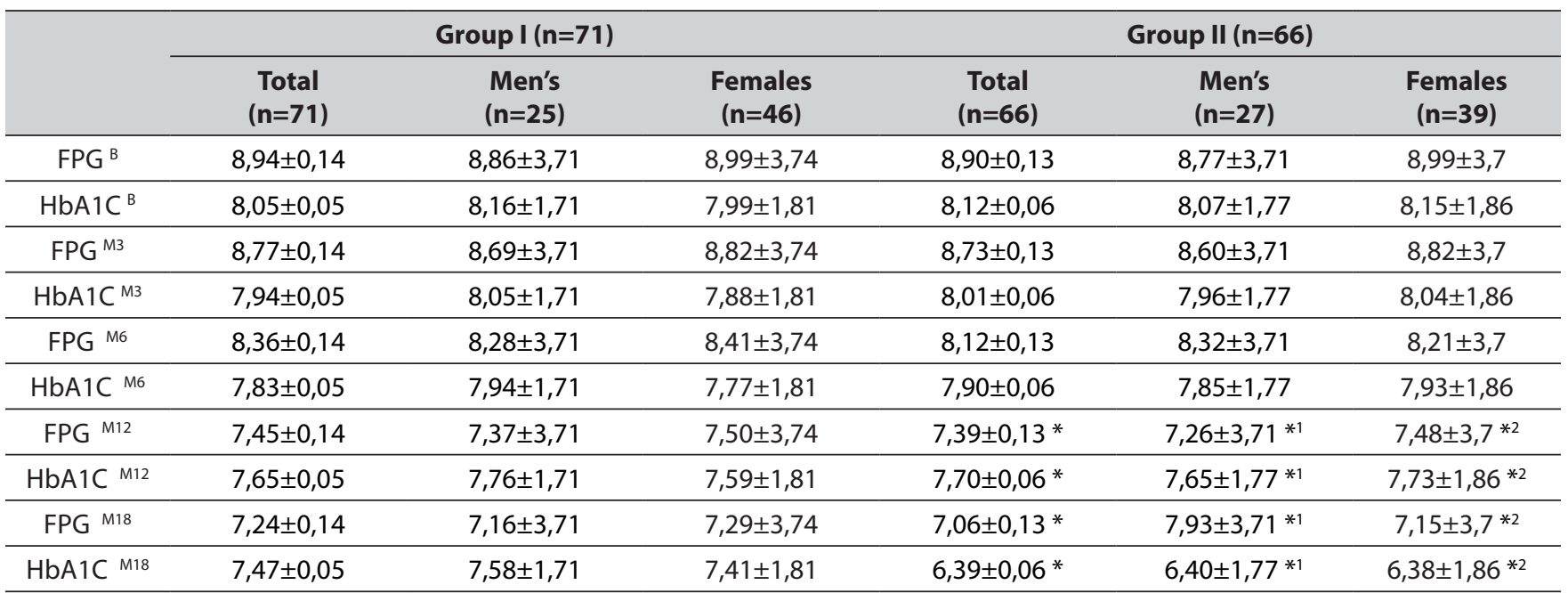

Note: $B$ - patient data at baseline; $\mathrm{M}$ - 3, 6, 12, 18 - patient data for 3, 6, 12, 18 months of observation of the respective patient groups; ${ }^{*}$ - statistically significant difference when comparing the indicators between the respective groups I and II $(p<0.05)$; where ${ }^{*} 1$ - between men and ${ }^{*} 2$ between women; Fasting plasma glucose - FPG.

FPG, HbA1C and AP levels with trace element and thyroid hormone levels, as well as the pharmacokinetic characteristics of this medicine. Additionally, a number of cases have been described in the literature when it is possible to use SGLT2 medicine as starting monotherapy, but these data are not yet sufficient for the routine clinical practice for the appropriate recommendations.

\section{CONCLUSIONS}

The incidence of these complications of the cardiovascular events and the renal complications can be reduced by providing patients with the adequate comprehensive treatment and controlling AP and hydrocarbon exchange, which may be indicative of the risk of their occurrence. The dapagliflozin study demonstrated the safety of its use and a slightly better effect on FPG, HbA1C, and AP compared to the standard metformin monotherapy. It is noteworthy that, starting from 12 months after the completing the course of the complex treatment and at the 18th month, the visit of the completion of the treatment and observation, between the anthropometric parameters (AP) and the hydrocarbon exchange (levels of FPG $\mathrm{HbA1C}$ ) of the patients of the 1st and the 2nd group, there was a statistically significant difference, the same the dynamics were also observed when comparing the sex between the two groups $(\mathrm{p}<0.05)$. A rather interesting finding during the study was the detection of $\mathrm{SCH}$ of the patients with T2DM and the concomitant obesity.

\section{REFERENCES}

1. Nathan D. Diabetes: advances in diagnosis and treatment. Jama, 2015;314(10):1052-1062.

2. Zhou B et al. Worldwide trends in diabetes since 1980: a pooled analysis of 751 population-based studies with 4.4 million participants. The Lancet, 2016;387(10027):1513-1530.
3. Batholomew C, Muzi L, Carl D. Diabetes increases the risk of depression: A systematic review, meta-analysis and estimates of population attributable fractions based on prospective studies. Preventive Medicine Reports. 2019;14:1-11. doi: 10.1016/j.pmedr.2019.100822

4. American Diabetes Association, et al. 10. Cardiovascular Disease and Risk Management: Standards of Medical Care in Diabetes—2020. Diabetes Care, 2020;43 (1):111-134. doi: 10.2337/dc20-5010

5. American Diabetes Association, et al. 2. Classification and Diagnosis of Diabetes: Standards of Medical Care in Diabetes — 2020. Diabetes Care, 2020;43(1):14-31. doi: 10.2337/dc20-S002

6. Buse J et al. 2019 update to: management of hyperglycemia in type 2 diabetes, 2018. A consensus report by the American Diabetes Association (ADA) and the European Association for the Study of Diabetes (EASD). Diabetes Care, 2020;43(2):487-493.

7. Aschner $P$ et al. Persistent poor glycemic control in individuals with type 2 diabetes in developing countries: 12 years of real-world evidence of the International Diabetes Management Practices Study (IDMPS). Diabetologia, 2020:1-11. doi: 10.1007/s00125-019-05078-3

8. Arow $M$ et al. Sodium-glucose cotransporter 2 inhibitor Dapagliflozin attenuates diabetic cardiomyopathy. Cardiovascular Diabetology, 2020;19(1):1-12. doi: 10.1186/s12933-019-0980-4

9. Huang $Z$ et al. Dapagliflozin restores insulin and growth hormone secretion in obese mice. Journal of Endocrinology, 2020;245(1):1-12.

10. Wiviott, Stephen D., et al. Dapagliflozin and cardiovascular outcomes in type 2 diabetes. New England Journal of Medicine, 2019;380(4):347357. doi: 10.1056/NEJMoa1812389

11. Heerspink H et al. "Kidney Outcomes Associated with Use of SGLT2 Inhibitors in Real-World Clinical Practice (CVD-REAL 3): a Multinational Observational Cohort Study."The Lancet Diabetes \& Endocrinology, 2020; 8(1):27-35. doi:10.1016/s2213-8587(19)30384-5

12. Zemel M. Medicinal Foods and Obesity. Journal of Medicinal Food, 2020. doi: $10.1089 / \mathrm{jmf} .2020 .29005 . \mathrm{mbz}$

13. Maiborodina D. Alternative Changes of Lipides Of Blood And Saliva In Patients With Generalized Periodontitis With Obesity Background. Biological Sciences, 2020; 2(47):50. 
14. Semlitsch T et al. Management of overweight and obesity in primary care - A systematic overview of international evidence-based guidelines. Obesity Reviews, 2019;20(9):1218-1230. doi: 10.1111/obr.12889

15. Goldman D et al. Extreme obesity is associated with angulation during inferior vena cava filter placement. Journal of Vascular Surgery: Venous and Lymphatic Disorders. 2020:1-7. doi: 10.1016/j.jvsv.2019.10.022

16. Joris P. et al. Effects of diet-induced weight loss on postprandial vascular function after consumption of a mixed meal: Results of a randomized controlled trial with abdominally obese men. Clinical Nutrition, 2020. doi: 10.1016/j.clnu.2020.01.006

17. Abdel-Ati A. et al. Study of Frequency of Prediabetes in Patients with Chronic Hepatitis C Virus Infection. 2020;7(4):227-232.

18. Blus E. et al. Usefulness of New Indicators of Obesity (BAI and VAI) in Estimation of Weight Reduction. Journal of the American College of Nutrition, 2020; 39(2):171-177. doi: 10.1080/07315724.2019.1630024

19. Mangla A. et al. Anthropometric Markers as a Paradigm for Obesity Risk Assessment. Journal of Biosciences and Medicines, 2020; 8(2):1-16. doi: 10.4236/jbm.2020.82001

The work was carried out in accordance with the plan of the research program of the Department of Therapy and Family Medicine of the Faculty of Postgraduate Education and Pre-University Training of Uzhhorod National University "Optimization of prevention and treatment of obesity and diabetes mellitus and Helicobacter490", where the authors are co-authors.

\section{ORCID and contributionship:}

Taras I. Griadil - 0000-0002-1048-0656 A,B,C

Ivan V. Chopey - 0000-0003-4626-0855 ${ }^{A, B, E}$

Kristian O. Debreceni - 0000-0001-7483-1307,D

Mykhaylo M. Hechko - 0000-0003-2793-5044 C,E

Yaroslav O. Mykhalko - 0000-0002-9890-6665 ${ }^{F}$

Snizhana V. Feysa-0000-0002-5064-8222 $2^{D, E}$

\section{Conflict of interest:}

The Authors declare no Conflict of interest.

\section{CORRESPONDING AUTHOR}

\section{Taras I. Griadil}

State Higher Educational Establishment «Uzhhgorod National University», Faculty of Postgraduate And Pre-University Education, Sobranetska str. 148, 88015, Uzhhgorod, Ukraine tel: +380990080218

e-mail: taras.griadil@uzhnu.edu.ua

Received: 17.01 .2020

Accepted: 05.03 .2020

A - Work concept and design, B - Data collection and analysis, C - Responsibility for statistical analysis, D -Writing the article, $\mathbf{E}$-Critical review, $\mathbf{F}$ - Final approval of the article 